\title{
In vitro gastric digestion of heat-induced aggregates of $\beta$-lactoglobulin
}

\author{
Malleswara R. Peram, Simon M. Loveday, Aiqian Ye, and Harjinder Singh ${ }^{1}$ \\ Riddet Institute, Massey University, Private Bag 11 222, Palmerston North 4442, New Zealand
}

\begin{abstract}
In vitro gastric digestion of heat-induced aggregates of $\beta$-lactoglobulin ( $\beta$-LG) in simulated gastric fluid was investigated using sodium dodecyl sulfate-PAGE (under nonreducing and reducing conditions), native PAGE, 2-dimensional electrophoresis, and size exclusion chromatography. Heating at $90^{\circ} \mathrm{C}$ significantly increased the digestibility of $\beta-\mathrm{LG}$, with a high initial digestion rate followed by a relatively constant rate of digestion at a high enzyme:substrate (E:S) ratio of $3: 1$. At a low E:S ratio (1:6), the rate of digestion of $\beta-\mathrm{LG}$ was slower, and intermediate- and low-molecular-weight species could be seen. The high-molecular-weight nonnative aggregates (e.g., pentamers, tetramers, and trimers) were digested relatively rapidly, whereas some of the nonnative dimers were resistant to digestion and others were digested rapidly. The intermediate-molecularweight species (21 to $23 \mathrm{kDa}$ ) were digested slowly. The digestibility of nonnative $\beta-\mathrm{LG}$ aggregates varied significantly depending on the E:S ratio and the types of aggregate. Further investigation is necessary to identify and characterize slowly digested dimers and species of intermediate molecular weight.
\end{abstract}

Key words: $\beta$-lactoglobulin, heat-induced aggregate, in vitro gastric digestibility, pepsin

\section{INTRODUCTION}

The majority of food proteins are subjected to technological processes such as heating, cooling, drying, exposure to high pressure, extrusion, irradiation, fermentation, homogenization, and membrane processes. The native structure of food proteins is readily altered as a result of these processing treatments (Li-Chan, 2004). The most common structural changes that food proteins undergo during processing include unfolding of the native tertiary structure and aggregation of the unfolded molecules. Such changes may have both desirable and undesirable effects on protein digestibility

Received July 2, 2012.

Accepted September 16, 2012.

${ }^{1}$ Corresponding author: H.Singh@massey.ac.nz
(Mills et al., 2009). For example, mild heating improves digestibility by partially denaturing the proteins, but severe heat treatment may reduce protein digestibility by cross-linking, racemization, and the Maillard reaction (Damodaran, 2007). A fundamental understanding of the structural modifications of proteins during food processing and relating these changes to digestibility could be useful in fabricating food products with improved nutritional properties.

$\beta$-Lactoglobulin is a globular protein and it comprises almost $50 \%$ of the total whey protein in bovine milk. At ambient temperature and physiological $\mathrm{pH}, \beta-\mathrm{LG}$ exists as a dimer, which dissociates into 2 identical monomers below pH 3 (Fox and McSweeney, 2003). Monomeric $\beta-\mathrm{LG}$ consists of $162 \mathrm{AA}$ residues and has a molecular weight of $18.3 \mathrm{kDa}$. It has 2 disulfide bonds at Cys 66-Cys 160 and Cys 106-Cys 119 and 1 free sulfhydryl group at Cys 121 . The secondary structure of $\beta$-LG contains $9 \beta$-strands: 8 are arranged to form a $\beta$-barrel and 1 forms a short $\alpha$-helix on the surface (Papiz et al., 1986). The center of the barrel is highly hydrophobic and capable of binding to vitamin A and fatty acids.

Native $\beta$-LG is resistant to some proteases, particularly pepsin, because of its unique structural stability at low pH (Miranda and Pelissier, 1983; Reddy et al., 1988). Most of the hydrophobic AA, which are potential cleavage sites for pepsin, are buried inside the hydrophobic core and are not readily accessible. Heating, high pressure treatment, addition of alcohols, and esterification have been reported to increase the susceptibility of $\beta$-LG to hydrolysis by pepsin (Chobert et al., 1995; Dalgalarrondo et al., 1995; Guo et al., 1995; Zeece et al., 2008). These treatments induce conformational changes in $\beta$-LG, resulting in increased exposure of peptic cleavage sites and thus increased susceptibility to pepsin action.

The heat-induced aggregation of $\beta$-LG has been extensively studied under a wide range of experimental conditions, such as $\mathrm{pH}$, ionic strength, protein concentration, and heating temperature (Xiong et al., 1993; Iametti et al., 1995; Manderson et al., 1998; Hoffmann and Van Mil, 1999). Heating above $70^{\circ} \mathrm{C}$ results in the dissociation of the dimer into monomers and the exposure of hydrophobic AA and free thiol/sulfhydryl groups (McKenzie, 1971; Iametti et al., 1995, 1996). 
This leads to the formation of a reactive monomer that undergoes sulfhydryl-disulfide exchange reactions to form nonnative dimers. These nonnative dimers react further to form intermediate oligomers and larger aggregates (Schokker et al., 1999).

Heating at 80 to $90^{\circ} \mathrm{C}$ induces conformational changes in the $\beta$-LG molecule that increase the exposure of peptic cleavage sites, thus increasing the hydrolysis of $\beta$-LG by pepsin (Reddy et al., 1988; Guo et al., 1995). Several different kinds of intermediates and aggregates are formed during heat treatment, and it is not known how different aggregates and modified monomers behave under gastrointestinal conditions, particularly in the presence of pepsin. Therefore, the objective of the present study was to examine the in vitro gastric digestibility of $\beta$-LG aggregates formed by heat treatment.

\section{MATERIALS AND METHODS}

\section{Materials}

Bovine $\beta$-LG (>90\% pure; genetic variants A and B) and pepsin (porcine gastric mucosa; 800 to 2,500 units/ mg of protein) were obtained from Sigma-Aldrich (St. Louis, MO). All other chemicals used were of analytical grade and obtained from Sigma Aldrich, unless otherwise specified.

\section{Heat Treatment of $\beta-L G$}

A stock solution of $\beta$-LG $(0.5 \%)$ was prepared by dissolving $\beta$-LG in Milli-Q water (Millipore, Billerica, MA). The $\mathrm{pH}$ of the solution was 7.4. Solutions of $\beta-\mathrm{LG}$ $(0.5 \%)$ were transferred into glass tubes and heated in a shaking water bath (BS-11, Jeio Tech Co. Ltd., Korea) at $90 \pm 0.1^{\circ} \mathrm{C}$ for different periods. After heating, the samples were immediately cooled in ice water for $5 \mathrm{~min}$ and were kept at room temperature.

\section{In Vitro Gastric Digestion}

The method described by Thomas et al. (2004) was used to determine digestibility of $\beta-\mathrm{LG}$ and its aggregates, with minor modifications. Simulated gastric fluid (SGF) was prepared according to the United States Pharmacopoeia (USP 24-NF 19; http://www.usp.org/ usp-nf) and consisted of $3.2 \mathrm{mg}$ of pepsin/mL in 0.035 $M \mathrm{NaCl}$ and $0.084 N \mathrm{HCl}$ at $\mathrm{pH} 1.2$. Aliquots of SGF were placed in glass vials and incubated in a shaking water bath at $37^{\circ} \mathrm{C}$ for 5 min before the addition of $\beta$-LG. The preheated $\beta$-LG solution was added to the SGF to give enzyme:substrate (E:S) ratios of $3: 1$ and 1:6 (wt/wt), and the mixtures were incubated at $37^{\circ} \mathrm{C}$ for the appropriate digestion times. Four samples [200 $\mu \mathrm{L}$ for alkaline native PAGE, $200 \mu \mathrm{L}$ for reduced SDSPAGE, $200 \mu \mathrm{L}$ for nonreduced SDS-PAGE, and $1 \mathrm{~mL}$ for size exclusion chromatography (SEC)-HPLC] were withdrawn after $0,0.5,1,2,5,10,30,60,90$, and 120 min. Control samples contained $\beta$-LG in SGF without pepsin. Samples of pepsin in SGF without $\beta$-LG were also prepared and treated to assess the auto-digestion of pepsin.

The samples for alkaline native PAGE were transferred to Eppendorf tubes containing $70 \mu \mathrm{L}$ of $0.2 \mathrm{M}$ $\mathrm{Na}_{2} \mathrm{CO}_{3}$ and $70 \mu \mathrm{L}$ of native PAGE sample buffer $(40 \%$ glycerol, $0.062 M$ Tris, and $0.01 \%$ bromophenol blue). The samples for reduced SDS-PAGE were transferred to Eppendorf tubes containing $70 \mu \mathrm{L}$ of $0.2 \mathrm{M} \mathrm{Na}_{2} \mathrm{CO}_{3}$ and $70 \mu \mathrm{L}$ of $5 \times$ Laemmli sample buffer ( $40 \%$ glycerol, $10 \%$ SDS, $0.33 M$ Tris, $0.05 \%$ bromophenol blue, and $5 \% \beta$-mercaptoethanol) and heated at $90^{\circ} \mathrm{C}$ for $5 \mathrm{~min}$. The samples for nonreduced SDS-PAGE were transferred to Eppendorf tubes containing $70 \mu \mathrm{L}$ of $0.2 \mathrm{M}$ $\mathrm{Na}_{2} \mathrm{CO}_{3}$ and $70 \mu \mathrm{L}$ of $5 \times$ Laemmli sample buffer. The samples for SEC-HPLC were transferred to Eppendorf tubes containing $350 \mu \mathrm{L}$ of $0.2 \mathrm{M} \mathrm{Na}_{2} \mathrm{CO}_{3}$. All samples were stored at $-20^{\circ} \mathrm{C}$ until further analysis.

\section{PAGE}

Electrophoresis experiments were carried out using a Mini Protean 3-cell system (Bio-Rad Laboratories, Hercules, CA). Alkaline native PAGE and SDS-PAGE (reduced and nonreduced) were performed as described by Manderson et al. (1998) using a 16\% resolving gel and a $4 \%$ stacking gel. Samples from each time point and controls were loaded into each well and subjected to electrophoretic separation at a constant voltage of $200 \mathrm{~V}$ for $1 \mathrm{~h}$. Following separation, the gels were stained with Coomassie Brilliant Blue staining solution (Coomassie Brilliant Blue R-250, 20\% isopropanol, and $10 \%$ acetic acid) for $30 \mathrm{~min}$ and destained with isopropanol:acetic acid solution (10\% each). The gels were scanned and quantified using the Molecular Imager Gel Doc XR system (Bio-Rad Laboratories) and Quantity One 1-D analysis software. Two-dimensional (2D) SDS-PAGE (first dimension nonreducing, second dimension reducing) was performed as described by Havea et al. (1998).

\section{Size Exclusion Chromatography}

Experiments were carried out using a Superdex 75 10/300 GL column (GE Healthcare, Piscataway, NJ; molecular mass range of 3,000 to 70,000 Da) attached to an AKTA FPLC system (GE Healthcare). The 


\section{Digestion time $(\min )$}

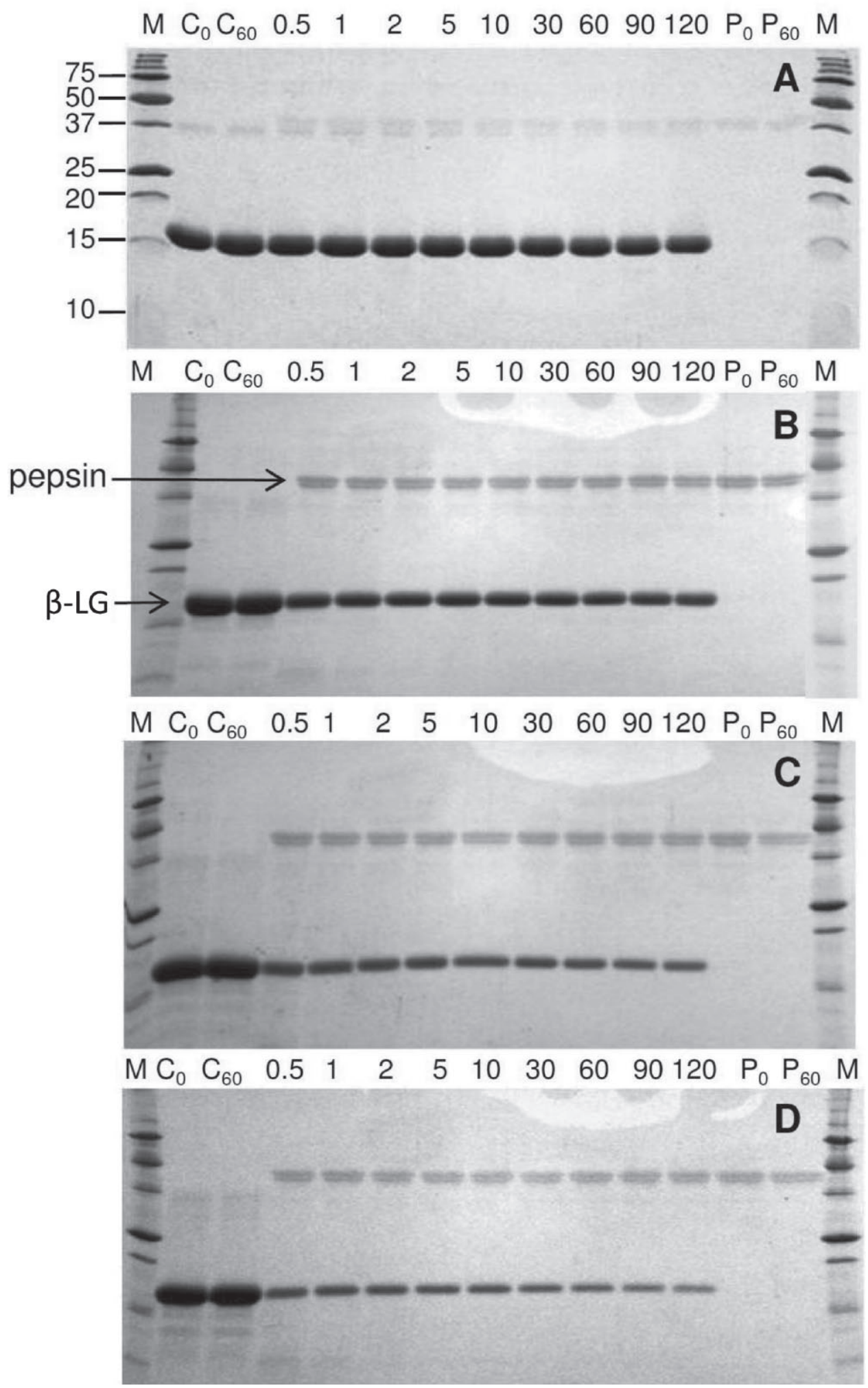

Figure 1. Reduced SDS-PAGE profiles of in vitro gastric digestion of (A) native $\beta$-LG, (B) $\beta$-LG heated at $90^{\circ} \mathrm{C}$ for 5 min, $(\mathrm{C}) \beta$-LG heated at $90^{\circ} \mathrm{C}$ for $60 \mathrm{~min}$, and (D) $\beta$-LG heated at $90^{\circ} \mathrm{C}$ for $120 \mathrm{~min}$. Pepsin: $\beta$-LG ratio was $3: 1$ (wt/wt). Lane M shows molecular weight markers. $\mathrm{C}_{0}$ and $\mathrm{C}_{60}$ represent preheated $\beta-\mathrm{LG}$ without pepsin in simulated gastric fluid at 0 and $60 \mathrm{~min}$. The number at the top of each lane represents the time of digestion (min); $\mathrm{P}_{0}$ and $\mathrm{P}_{60}$ represent pepsin controls at 0 and $60 \mathrm{~min}$. 


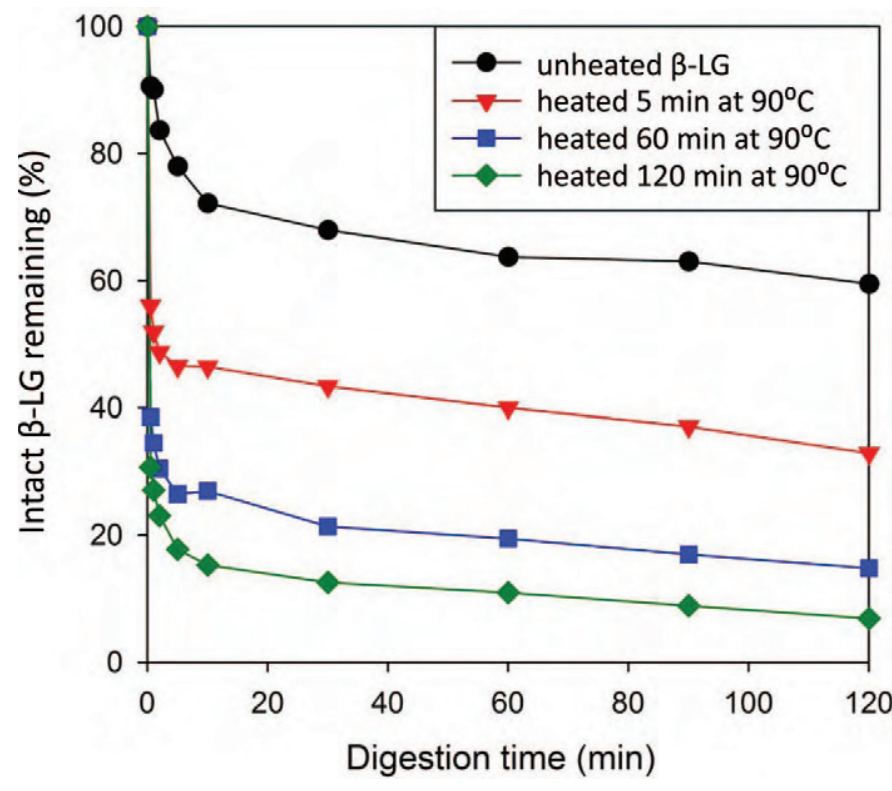

Figure 2. Quantification of intact $\beta-\mathrm{LG}$ remaining after gastric digestion of native and heated $\beta-\mathrm{LG}\left(90^{\circ} \mathrm{C}\right.$ for 5,60 , and $\left.120 \mathrm{~min}\right)$. Color version available in the online PDF.

samples were filtered through a $0.22-\mu \mathrm{m}$ membrane filter (Millipore), and $200 \mu \mathrm{L}$ of sample was applied to the column equilibrated with $0.02 M$ imidazole in 0.05 $M \mathrm{NaCl}, \mathrm{pH} 7.0$, at a flow rate of $0.3 \mathrm{~mL} / \mathrm{min}$. The UV absorption was measured at $280 \mathrm{~nm}$.

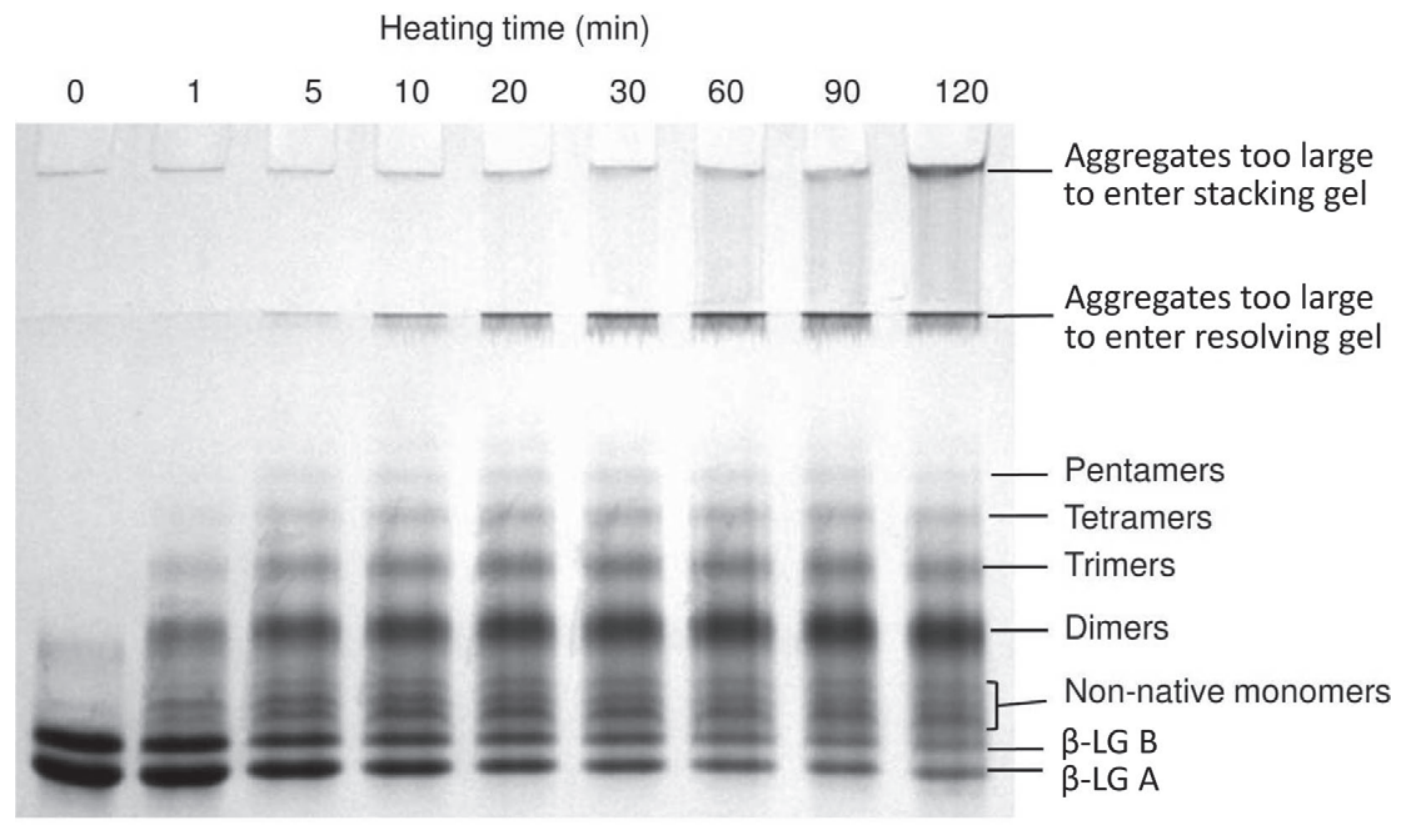

Figure 3. Alkaline native PAGE of $\beta$-LG heated at $90^{\circ} \mathrm{C}$ for $0,1,5,10,20,30,60,90$, and 120 min. 
after 120 min of digestion was $65 \%$ for native $\beta$-LG, and was 33, 15, and $7 \%$ when $\beta$-LG was heated at $90^{\circ} \mathrm{C}$ for 5,60 , and $120 \mathrm{~min}$, respectively. These results suggested that the digestibility of $\beta-L G$ increased as the heating time was increased from 5 to $120 \mathrm{~min}$. In the case of heated $\beta$-LG, we observed a rapid loss of $\beta$-LG in the initial $0.5 \mathrm{~min}$ of digestion, and heating for longer increased the amount of $\beta-\mathrm{LG}$ that was lost initially. Thereafter, the amount of $\beta-\mathrm{LG}$ decreased slowly during $120 \mathrm{~min}$ of digestion. In agreement with other studies (Reddy et al., 1988; Dalgalarrondo et al., 1995), these results confirm that native $\beta-\mathrm{LG}$ is largely resistant to digestion by pepsin. Most of the hydrophobic amino acids are buried inside the $\beta$-barrel and are not easily accessible to pepsin, but heating causes the unfolding of protein molecules, thereby increasing the accessibility of exposed hydrophobic amino acids to pepsin (Reddy et al., 1988; Schmidt and Van Markwijk,
1993). In addition, the present study showed that the rate of digestion of heated $\beta-L G$ was very high in the initial few minutes, and subsequent digestion was much slower, possibly indicating different susceptibilities to pepsin of the intermediate species created during the heat-induced unfolding and aggregation process. To explore this further, we examined the relative digestibilities of different aggregates and intermediates produced during the heat treatment of $\beta-\mathrm{LG}$, using an in vitro gastric digestion model.

The alkaline native PAGE patterns of $\beta$-LG heated at $90^{\circ} \mathrm{C}$ for $0,1,5,10,20,30,60,90$, and $120 \mathrm{~min}$ in Milli-Q water are shown in Figure 3. As expected, heating resulted in a decrease in the intensity of the native $\beta$-LG band and a corresponding increase in the intensity of protein bands with electrophoretic mobility lower than that of native $\beta$-LG. These bands were identified as nonnative monomers, dimers, trimers,
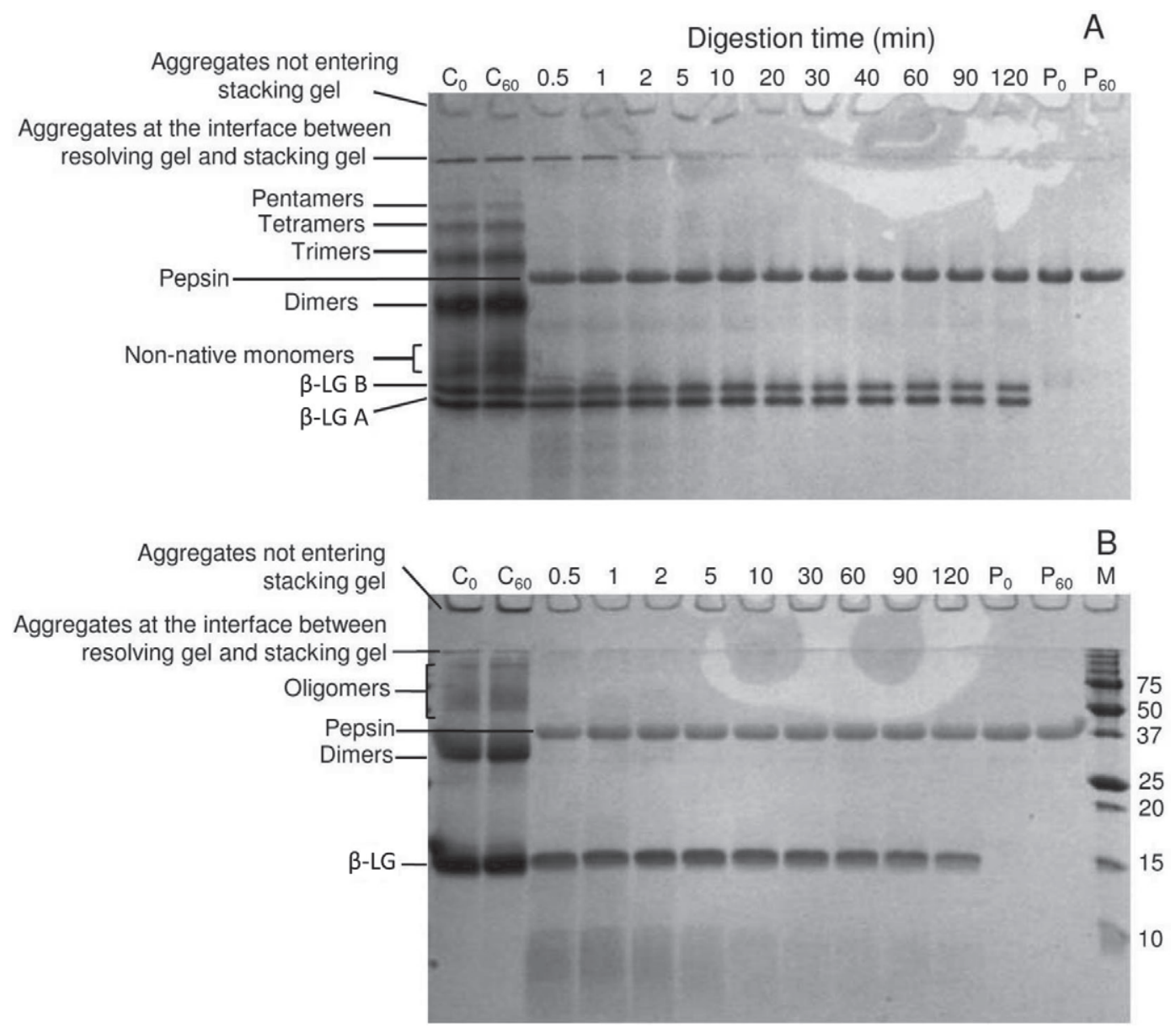

Figure 4. Gastric digestion of $\beta-\mathrm{LG}$ heated at $90^{\circ} \mathrm{C}$ for $60 \mathrm{~min}$ and analyzed by (A) native PAGE and (B) nonreduced SDS-PAGE. Pepsin: $\beta$ $\mathrm{LG}$ ratio was $3: 1$ (wt/wt). Lane $\mathrm{M}$ shows molecular weight markers. $\mathrm{C}_{0}$ and $\mathrm{C}_{60}$ represent preheated $\beta$-LG without pepsin in simulated gastric fluid at 0 and 60 min. The number at the top of each lane represents the time of digestion $(\mathrm{min}) ; \mathrm{P}_{0}$ and $\mathrm{P}_{60}$ represent pepsin controls at 0 and $60 \mathrm{~min}$. 

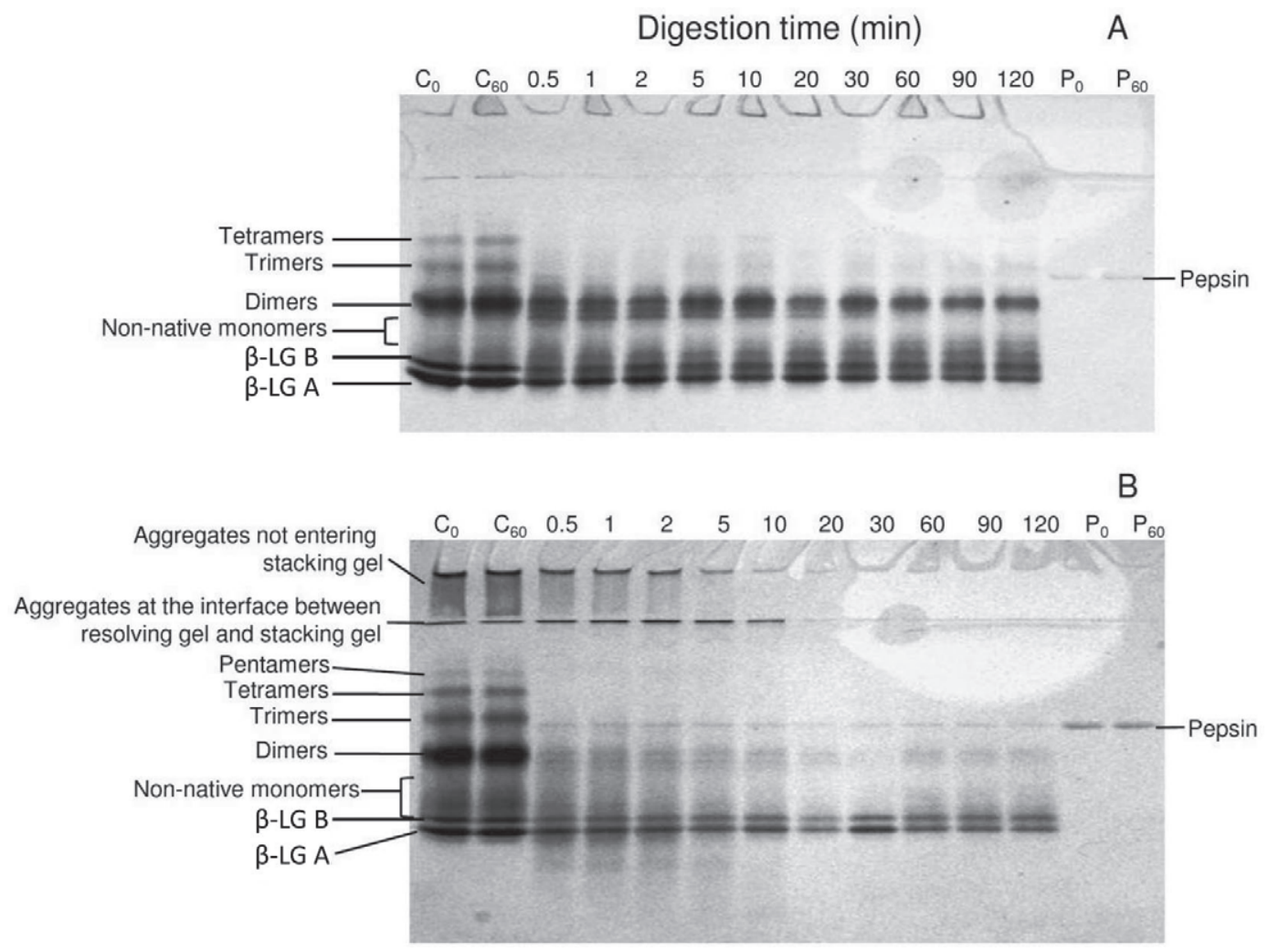

Figure 5. Alkaline native PAGE analysis of in vitro gastric digestion of $\beta$-LG heated at $90^{\circ} \mathrm{C}$ for (A) 5 min and (B) 120 min. Pepsin: $\beta$-LG ratio was 1:6 (wt/wt). Lane $\mathrm{M}$ shows molecular weight markers. $\mathrm{C}_{0}$ and $\mathrm{C}_{60}$ represent preheated $\beta$-LG without pepsin in simulated gastric fluid at 0 and 60 min. The number at the top of each lane represents the time of digestion $(\mathrm{min}) ; \mathrm{P}_{0}$ and $\mathrm{P}_{60}$ represent pepsin controls at 0 and 60 min.

tetramers, pentamers, and so on, by comparison with previous results (Manderson et al., 1998; Schokker et al., 1999). Nonnative monomers may have undergone irreversible conformational alterations (Harwalkar, 1980), such as those induced by intramolecular disulfide interchange (Creamer et al., 2004). In addition, some large aggregates that did not enter the resolving gel and the stacking gel were also observed. A small quantity of $\beta$-LG remained in the native state after heating at $90^{\circ} \mathrm{C}$ for $120 \mathrm{~min}$.

To understand the digestion behavior of aggregates formed during the heat treatment of $\beta-\mathrm{LG}$, we analyzed the in vitro gastric digestion profile of $\beta$-LG heated at $90^{\circ} \mathrm{C}$ for $60 \mathrm{~min}$ by alkaline native PAGE (Figure 4A) and nonreduced SDS-PAGE (Figure 4B). Alkaline native PAGE is used to study aggregates that are linked through both disulfide and noncovalent bonds, whereas nonreduced SDS-PAGE is used only for disulfide-linked aggregates because it dissociates the aggregates linked through noncovalent bonds. The alkaline native PAGE analysis showed that heating $\beta-\mathrm{LG}$ at $90^{\circ} \mathrm{C}$ for $60 \mathrm{~min}$ resulted in the formation of nonnative aggregates of different sizes (i.e., dimers, trimers, tetramers, pentamers, and aggregates) present at the interface between the resolving gel and the stacking gel. The bands related to trimers, tetramers, and pentamers (oligomers) were not well separated in nonreduced SDS-PAGE. Most of the nonnative aggregates were completely digested by pepsin within $0.5 \mathrm{~min}$. Aggregates present at the interface between the resolving gel and the stacking gel were digested by pepsin within $5 \mathrm{~min}$. The intensity of the native $\beta$-LG band changed little after 120 min of digestion with pepsin. From these results, it is clear that the rapid decrease in the intensity of the $\beta$-LG band during the initial $0.5 \mathrm{~min}$ of digestion in reduced SDS-PAGE gels (Figures 1B to 1D) was due to the complete digestion of disulfide-linked aggregates, which appear as monomeric $\beta$-LG bands in reduced SDS-PAGE gels; the $\beta$-mercaptoethanol present in the reduced SDS-PAGE sample buffer disrupts all disulfide-linked aggregates.

The rate of protein digestion was greatly influenced by the E:S ratio used in the study. The exact ratio of pepsin to food protein present during the human digestive process is not well known and varies with the nature of the food consumed. We used a lower E:S ratio (1:6) to further understand the digestion behavior of 
heat-induced aggregates of $\beta-\mathrm{LG}$, which were digested very rapidly at the higher E:S ratio (3:1). The supplementary material (Figure S1, available online at http:// www.journalofdairyscience.org/) contains a side-by-side comparison showing how the E:S ratio affected digestion of $\beta-\mathrm{LG}$ heated at $90^{\circ} \mathrm{C}$ for 5,60 , or $120 \mathrm{~min}$.

In vitro gastric digestion of $\beta-\mathrm{LG}$ heated at $90^{\circ} \mathrm{C}$ for 5 and 120 min was performed using SGF at pH 1.2 and a pepsin: $\beta$-LG ratio of 1:6. Alkaline native PAGE (Figures $5 \mathrm{~A}$ and $5 \mathrm{~B}$ ) analysis showed that heating $\beta$-LG at $90^{\circ} \mathrm{C}$ for $5 \mathrm{~min}$ resulted in the formation of nonnative aggregates of different sizes (i.e., dimers, trimers, and tetramers; Figure 5A). The trimers and tetramers were completely digested within $0.5 \mathrm{~min}$, but the intensity of the dimer band decreased during the first $60 \mathrm{~min}$ of digestion and remained almost constant thereafter. A small decrease in the intensity of the $\beta-\mathrm{LG} A$ and $\mathrm{B}$ bands was observed after $0.5 \mathrm{~min}$ of digestion compared with the control samples. Heating $\beta-\mathrm{LG}$ at $90^{\circ} \mathrm{C}$ for $120 \mathrm{~min}$ (Figure 5B) resulted in the formation of more aggregates: dimers, trimers, tetramers, pentamers, and large aggregates (aggregates at the interface of the stacking and resolving gels and aggregates that were too large to enter the stacking gel; Figure 5B). The dimers, trimers, tetramers, and pentamers were completely digested by pepsin within the first 0.5 min. Large aggregates were digested by pepsin within $10 \mathrm{~min}$. A slight decrease in the intensity of the $\beta$-LG band was observed after 0.5 min of digestion.

Analysis by nonreduced SDS-PAGE (Figures 6A and $6 \mathrm{~B}$ ) showed similar trends. Heating at $90^{\circ} \mathrm{C}$ for 5 min resulted in the formation of aggregates of different sizes (i.e., dimers and oligomers; Figure 6A). All oligomers were digested completely within $0.5 \mathrm{~min}$ but some dimers were quite resistant to digestion. The dimer band decreased in intensity in the first $0.5 \mathrm{~min}$ and then remained constant until 120 min of digestion. Some bands were observed just above the $\beta$-LG band, which we have termed "intermediate molecular weight" (IMW) species. These IMW species were digested slowly. Some peptide bands with a molecular mass $<10 \mathrm{kDa}$ were observed and were fully digested within $60 \mathrm{~min}$. In addition to dimers and oligomers, large aggregates were also formed when $\beta-\mathrm{LG}$ was heated at $90^{\circ} \mathrm{C}$ for $120 \mathrm{~min}$ (Figure 6B). The dimers and oligomers were completely digested by pepsin in $0.5 \mathrm{~min}$, whereas

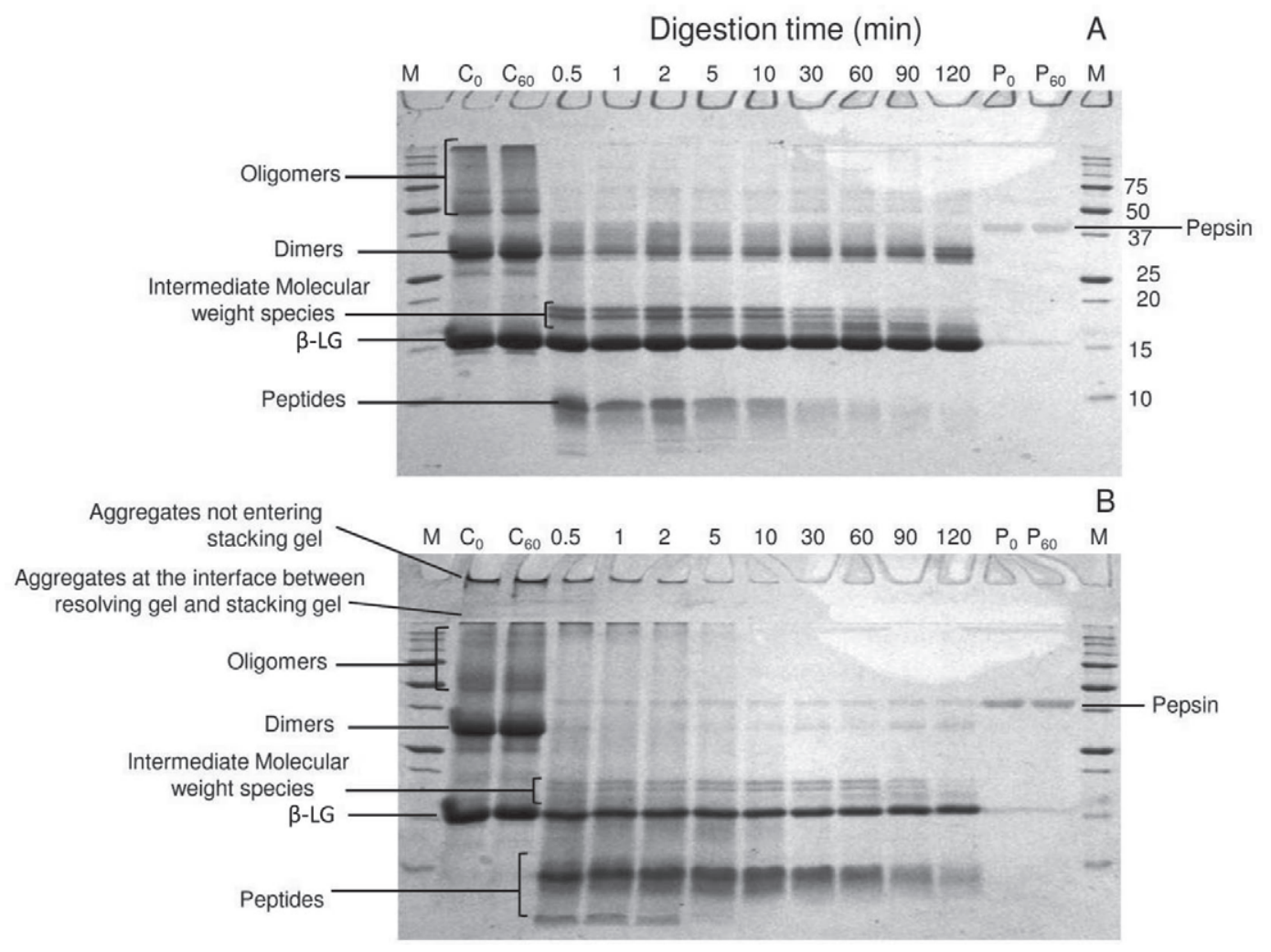

Figure 6. Nonreduced SDS-PAGE analysis of in vitro gastric digestion of $\beta$-LG heated at $90^{\circ} \mathrm{C}$ for (A) 5 min and (B) 120 min. Pepsin: $\beta$-LG ratio was 1:6 (wt/wt). Lane $M$ shows molecular weight markers. $C_{0}$ and $\mathrm{C}_{60}$ represent preheated $\beta$-LG without pepsin in simulated gastric fluid at 0 and 60 min. The number at the top of each lane represents the time of digestion (min); $\mathrm{P}_{0}$ and $\mathrm{P}_{60}$ represent pepsin controls at 0 and 60 min. 

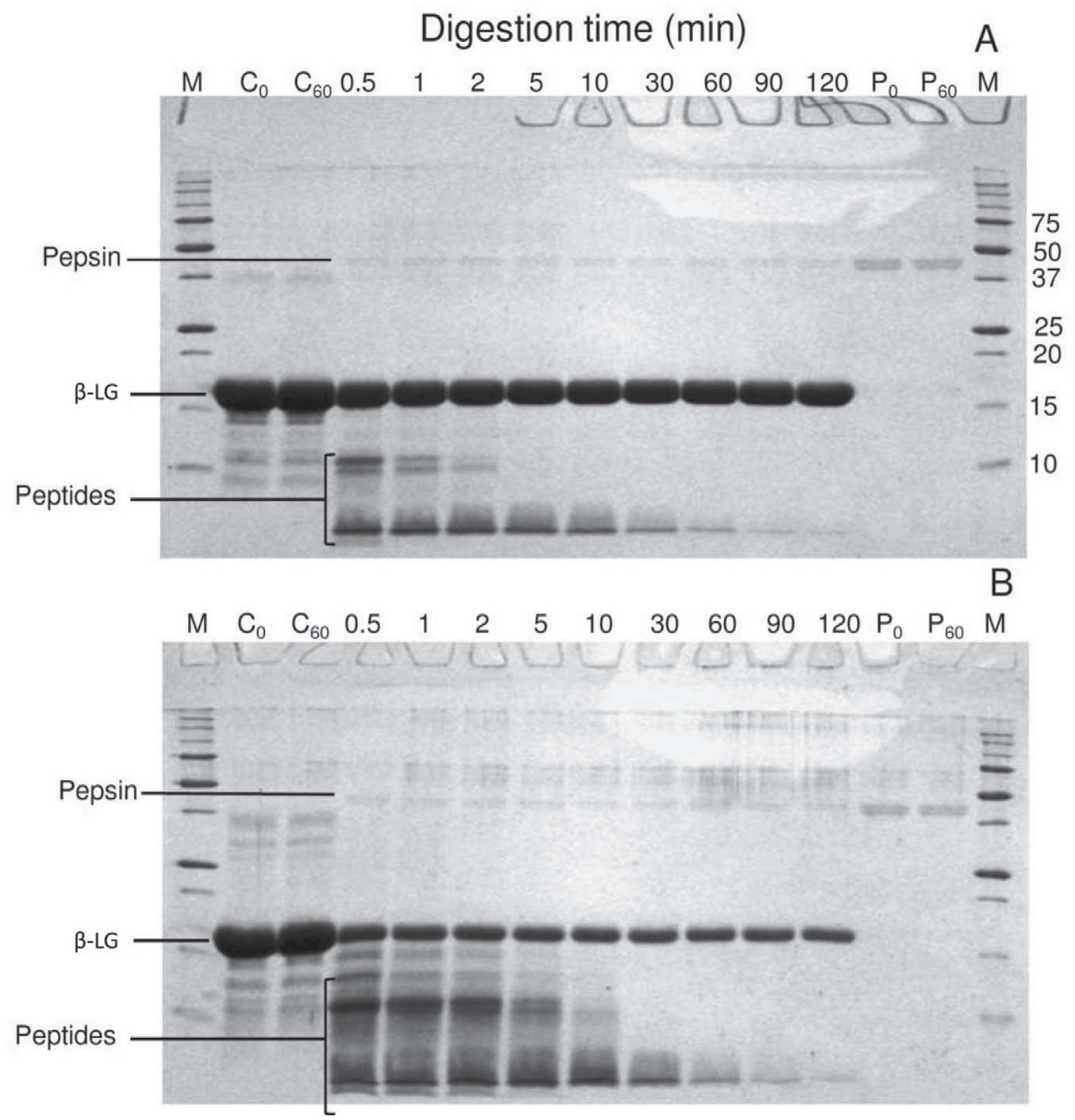

Figure 7. Reduced SDS-PAGE analysis of in vitro gastric digestion of $\beta$-LG heated at $90^{\circ} \mathrm{C}$ for (A) 5 min and (B) 120 min. Pepsin: $\beta$-LG ratio was 1:6 (wt/wt). Lane $\mathrm{M}$ shows molecular weight markers. $\mathrm{C}_{0}$ and $\mathrm{C}_{60}$ represent preheated $\beta$-LG without pepsin in simulated gastric fluid at 0 and $60 \mathrm{~min}$. The number at the top of each lane represents the time of digestion (min); $\mathrm{P}_{0}$ and $\mathrm{P}_{60}$ represent pepsin controls at 0 and 60 min.

the large aggregates were digested by pepsin within 10 min. The IMW species formed after 120 min of heating followed almost the same digestion pattern as those formed after $5 \mathrm{~min}$ of heating. Digestion for 0.5 min produced several peptides with molecular masses $<10 \mathrm{kDa}$; some were digested completely in $2 \mathrm{~min}$ and some were digested slowly and resisted $120 \mathrm{~min}$ of digestion.

These results clearly showed that the stable highmolecular-weight aggregates (e.g., pentamers, tetramers, and trimers) generated during the heat-induced aggregation of $\beta-\mathrm{LG}$ were digested relatively rapidly; in contrast, some of the nonnative dimers were relatively resistant to digestion and others were digested readily. It is interesting to note that the dimers formed during the early stages of heating (e.g., 5 min of heating) were quite resistant to digestion, whereas those formed after $120 \mathrm{~min}$ of heating were easily digested by pepsin. The dimers formed during the early stages of unfolding probably retained some of their secondary and tertiary structural features and the pepsin cleavage sites remained buried and were not accessible to pepsin. Heating for longer resulted in significant changes in the secondary and tertiary structures of the dimers and consequently promoted their digestibility with pepsin. Further work is required to understand the structural changes in these dimers with an increase in the heating time. The IMW species are also interesting. They 
were probably formed from interactions of the nonnative monomeric $\beta$-LG with the exposed thiol group and peptides resulting from the digestion of nonnative aggregates.

Reduced SDS-PAGE analysis of the in vitro gastric digestion of $\beta$-LG heated at $90^{\circ} \mathrm{C}$ for 5 and $120 \mathrm{~min}$ using a pepsin: $\beta-\mathrm{LG}$ ratio of 1:6 is shown in Figures $7 \mathrm{~A}$ and $7 \mathrm{~B}$. At an E:S ratio of 1:6, the rate of digestion of $\beta$-LG was slower than that observed at an E:S ratio of $3: 1$, and several low molecular weight peptides $(<10 \mathrm{kDa})$ were observed after $0.5 \mathrm{~min}$ of digestion (Figure 7B). Most of these peptides were further hydrolyzed during $120 \mathrm{~min}$ of digestion. The number of peptides observed after pepsin digestion was greater in the reduced SDS-PAGE gels (Figure 7B) than in the nonreduced SDS-PAGE gels (Figure 6B), as indicated by the larger number of bands and wider spreading of bands below the $\beta$-LG band. This may have been because some of the peptides were cross-linked through disulfide bonds to form IMW species; these species were broken down by the $\beta$-mercaptoethanol present in the sample buffer of the reduced SDS-PAGE. To explore this further, the IMW species observed in the nonreduced SDS-PAGE were characterized using 2D electrophoresis (SDS-PAGE nonreduced and then
SDS-PAGE reduced). $\beta$-Lactoglobulin heated at $90^{\circ} \mathrm{C}$ for $5 \mathrm{~min}$ and digested with pepsin for $10 \mathrm{~min}$ was analyzed (Figure 8). The first dimension (nonreduced SDS-PAGE) pattern of the heated and digested $\beta$-LG sample showed bands corresponding to native monomeric $\beta$-LG, IMW species, and nonnative dimers, and very faint bands corresponding to nonnative oligomers. In the second dimension (reduced SDS-PAGE), all the oligomers and dimers appeared as monomeric $\beta$-LG, whereas the IMW species appeared as 2 spots, one at the monomeric $\beta-\mathrm{LG}$ position and another faint band just below the monomeric $\beta$-LG position. These results indicate that the IMW species consisted of nonnative monomeric $\beta$-LG and some peptides linked through disulfide bonds.

The in vitro gastric digestion of $\beta-\mathrm{LG}$ heated at $90^{\circ} \mathrm{C}$ for 5 min was analyzed by SEC-HPLC to observe changes in the digestion pattern of the peptides (Figure 9 ). Heated $\beta$-LG showed 2 peaks corresponding to nonnative dimers and native-like $\beta-\mathrm{LG}$ and eluting at retention times of 33 and 38 min, respectively. Pepsin was eluted as a single peak with a retention time of $30 \mathrm{~min}$. After $1 \mathrm{~min}$ of digestion, the peaks of nonnative dimers and native-like $\beta$-LG decreased, and 6 peaks (labeled P1 to P6 in Figure 9) corresponding to peptides

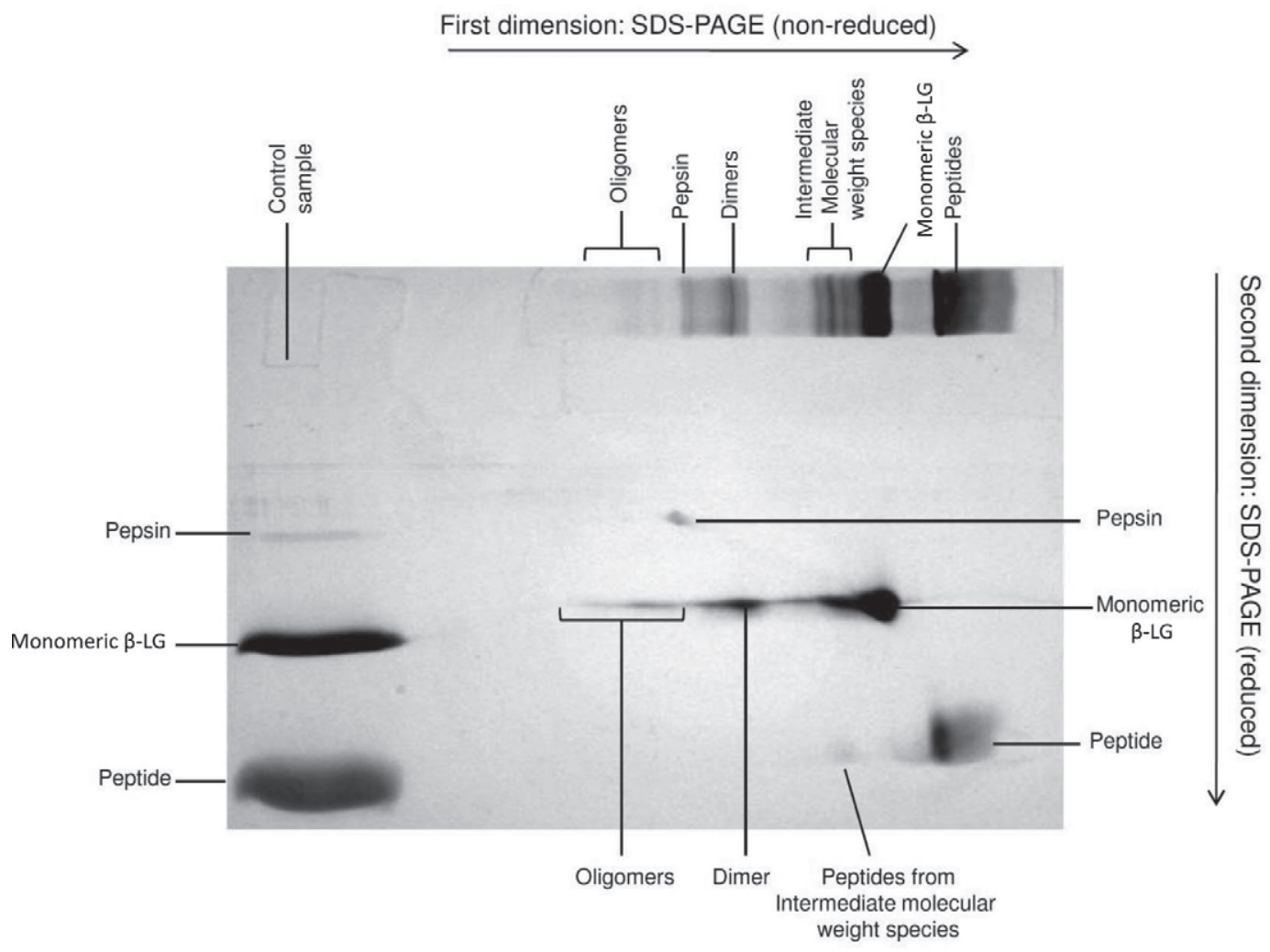

Figure 8. Two-dimensional electrophoresis (first dimension: nonreducing SDS-PAGE, second dimension: reducing SDS-PAGE) of $\beta$-LG heated at $90^{\circ} \mathrm{C}$ for $5 \mathrm{~min}$ and digested with pepsin for $10 \mathrm{~min}$. 


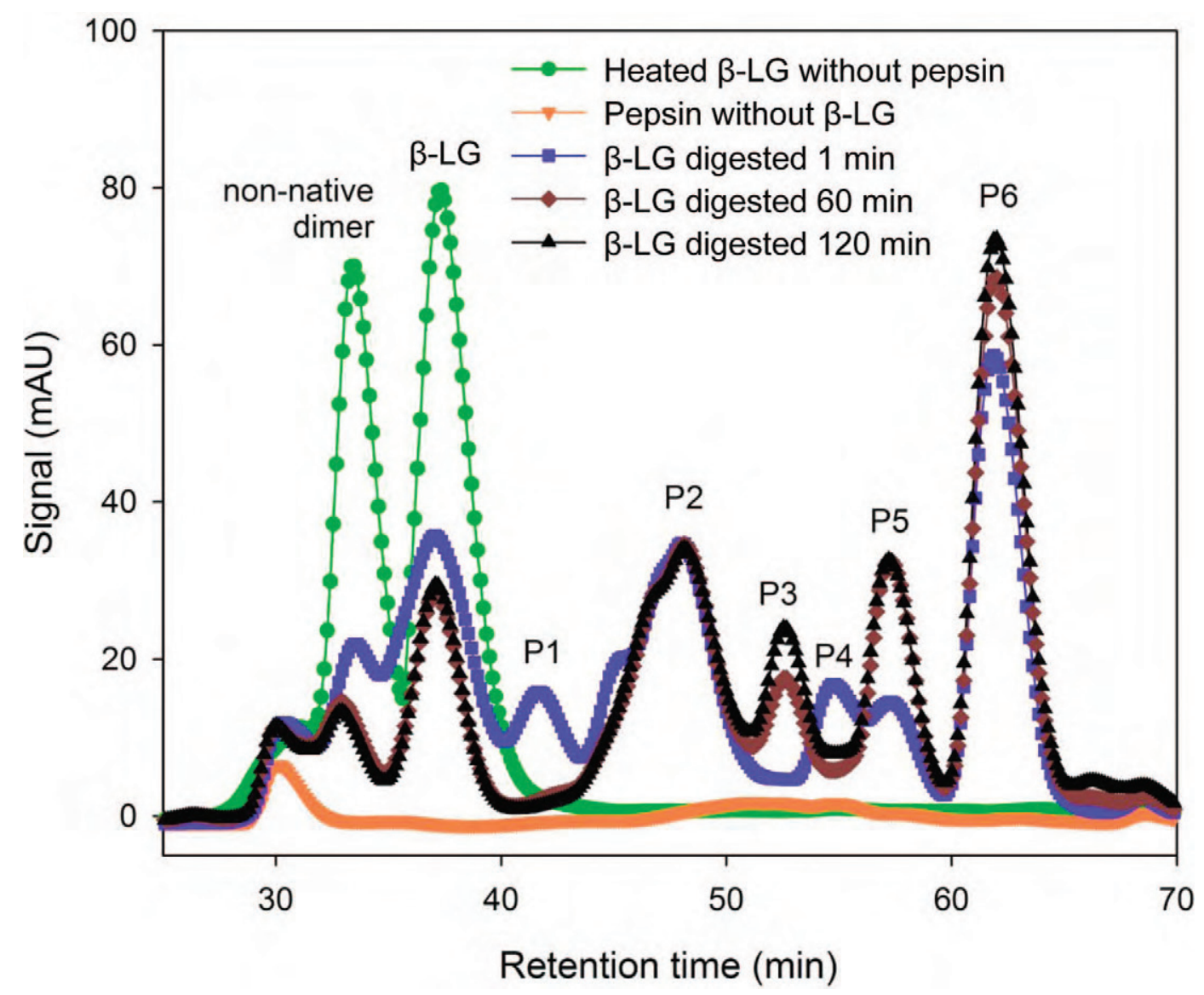

Figure 9. Size exclusion chromatography-HPLC profile of gastric digestion of $\beta$-LG heated at $90^{\circ} \mathrm{C}$ for 5 min. Peptide peaks are designated $\mathrm{P} 1$ to $\mathrm{P} 6$. Color version available in the online PDF.

were generated. Peak height for nonnative aggregates and native-like $\beta$-LG did not change significantly beyond $60 \mathrm{~min}$. The peptides indicated by peaks 1 and 4 were completely digested, whereas those corresponding to peaks 5 and 6 increased during the first $60 \mathrm{~min}$ of digestion; peak height did not change significantly thereafter. Peak 3 increased throughout $120 \mathrm{~min}$ of digestion, whereas peak 2 appeared after the first minute of digestion and neither increased nor decreased with longer digestion. The number of peptides observed after $\beta$-LG digestion with pepsin was greater for SEC-HPLC than for SDS-PAGE (Figure 7A), because of the inability of SDS-PAGE gels to detect lower-molecular-weight peptides.

A schematic diagram showing the possible sequence of events during the formation of heat-induced aggregates of $\beta-\mathrm{LG}$ and their digestion in the gastric environment is given in Figure 10. At room temperature and neutral $\mathrm{pH}, \beta-\mathrm{LG}$ exists as a noncovalently linked dimer. Upon heating to $90^{\circ} \mathrm{C}$, this dimer dissociates into monomers, which partially unfold, leading to the formation of nonnative monomers and the exposure of inner hydrophobic AA and the free thiol group. Two types of nonnative monomers exist, one with the free thiol group at Cys 121 and the other with the free thiol group at Cys 119 (Creamer et al., 2004). The nonnative monomer with the free Cys 119 is formed from the intramolecular sulfhydryl-disulfide exchange reaction between Cys 121 and Cys 106-Cys 119. The nonnative monomer with the free Cys 121 undergoes intermolecular disulfide exchange reactions, leading to the formation of dimers and large aggregates (Creamer et al., 2004). On cooling, the nonnative monomer with the free Cys 121 switches back to a native monomer, whereas the nonnative monomer with the free Cys 119 remains as a nonnative monomer. A heated and cooled $\beta$-LG solution contains native monomers with free Cys 121, nonnative monomers, and other disulfide-linked aggregates. The digestibility of heat-induced aggregates of $\beta$-LG varies significantly. All aggregates and intermediate species, except some dimers, are readily digested, suggesting that aggregation does not hinder access of pepsin to the cleavage sites. New IMW fragments that are linked through disulfide bonds are generated from 


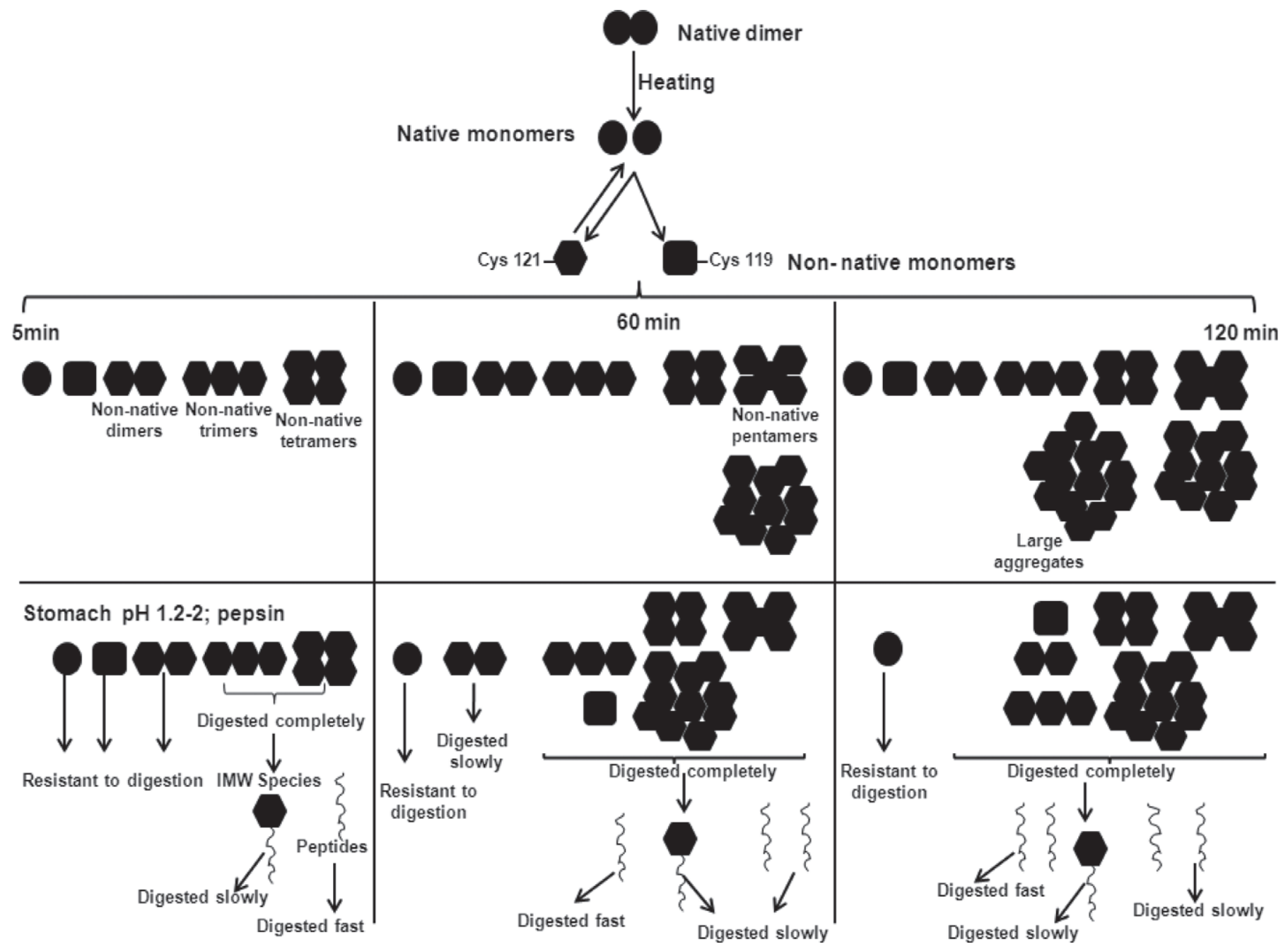

Figure 10. Scheme of events taking place during the pepsin digestion of heat-induced aggregates of $\beta$-LG. IMW $=$ intermediate molecular weight.

the hydrolysis of the aggregates. Further studies are necessary to understand the structural aspects of slowly and rapidly digested dimers of $\beta-\mathrm{LG}$, and the peptides generated during the digestion need to be identified.

\section{REFERENCES}

Chobert, J. M., L. Briand, V. Grinberg, and T. Haertlé. 1995. Impact of esterification on the folding and the susceptibility to peptic proteolysis of $\beta$-lactoglobulin. Biochim. Biophys. Acta 1248:170-176.

Creamer, L. K., A. Bienvenue, H. Nilsson, M. Paulsson, M. van Wanroij, E. K. Lowe, S. G. Anema, M. J. Boland, and R. JimenezFlores. 2004. Heat-induced redistribution of disulfide bonds in milk proteins. 1. Bovine $\beta$-lactoglobulin. J. Agric. Food Chem. $52: 7660-7668$

Dalgalarrondo, M., E. Dufour, J. M. Chobert, C. Bertrand-Harb, and T. Haertlé. 1995. Proteolysis of $\beta$-lactoglobulin and $\beta$-casein by pepsin in ethanolic media. Int. Dairy J. 5:1-14.

Damodaran, S. 2007. Amino acids, peptides, and proteins. Pages 217329 in Fennema's Food Chemistry. 4th ed. S. Damodaran, K. L. Parkin, and O. R. Fennema, ed. CRC Press, Boca Raton, FL.
Fox, P. F., and P. L. H. McSweeney. 2003. Chapter 7 in Advanced Dairy Chemistry. 3rd ed. Vol. 1, Part A. Kluwer Academic/Plenum Publishers, New York, NY.

Guo, M. R., P. F. Fox, A. Flynn, and P. S. Kindstedt. 1995. Susceptibility of $\beta$-lactoglobulin and sodium caseinate to proteolysis by pepsin and trypsin. J. Dairy Sci. 78:2336-2344.

Harwalkar, V. R. 1980. Measurement of thermal denaturation of $\beta$-lactoglobulin at pH 2.5. J. Dairy Sci. 63:1043-1051.

Havea, P., H. Singh, L. K. Creamer, and O. H. Campanella. 1998. Electrophoretic characterization of the protein products formed during heat treatment of whey protein concentrate solutions. J. Dairy Res. 65:79-91.

Hoffmann, M. A. M., and P. J. J. M. Van Mil. 1999. Heat-induced aggregation of $\beta$-lactoglobulin as a function of pH. J. Agric. Food Chem. 47:1898-1905.

Iametti, S., S. Cairoli, B. De Gregori, and F. Bonomi. 1995. Modifications of high-order structures upon heating of $\beta$-lactoglobulin: Dependence on the protein concentration. J. Agric. Food Chem. 43:53-58

Iametti, S., B. De Gregori, G. Vecchio, and F. Bonomi. 1996. Modifications occur at different structural levels during the heat denaturation of $\beta$-lactoglobulin. Eur. J. Biochem. 237:106-112. 
Li-Chan, E. C. Y. 2004. Properties of proteins in food systems: An introduction. Pages 2-26 in Proteins in Food Processing. 1st ed. R. Y. Yada, ed. Woodhead Publishing, Cambridge, UK.

Manderson, G. A., M. J. Hardman, and L. K. Creamer. 1998. Effect of heat treatment on the conformation and aggregation of $\beta$-lactoglobulin A, B, and C. J. Agric. Food Chem. 46:5052-5061.

McKenzie, H. A. 1971. $\beta$-Lactoglobulins. Pages 257-330 in Milk Proteins. H. A. McKenzie, ed. Academic Press, New York, NY.

Mills, E. N. C., A. I. Sancho, N. M. Rigby, J. A. Jenkins, and A. R. Mackie. 2009. Impact of food processing on the structural and allergenic properties of food allergens. Mol. Nutr. Food Res. 53:963-969.

Miranda, G., and J. P. Pelissier. 1983. Kinetic studies of in vivo digestion of bovine unheated skim-milk proteins in the rat stomach. J. Dairy Res. 50:27-36.

Papiz, M. Z., L. Sawyer, E. E. Eliopoulos, A. C. T. North, J. B. C. Findlay, R. Sivaprasadarao, T. A. Jones, M. E. Newcomer, and P. J. Kraulis. 1986. The structure of $\beta$-lactoglobulin and its similarity to plasma retinol-binding protein. Nature 324:383-385.

Reddy, I. M., N. K. D. Kella, and J. E. Kinsella. 1988. Structural and conformational basis of the resistance of $\beta$-lactoglobulin to peptic and chymotryptic digestion. J. Agric. Food Chem. 36:737-741.

Schmidt, D. G., and B. W. Van Markwijk. 1993. Enzymatic hydrolysis of whey proteins: Influence of heat treatment of $\alpha$-lactalbumin and $\beta$-lactoglobulin on their proteolysis by pepsin and papain. Neth. Milk Dairy J. 47:15-22.

Schokker, E. P., H. Singh, D. N. Pinder, G. E. Norris, and L. K. Creamer. 1999. Characterization of intermediates formed during heat-induced aggregation of $\beta$-lactoglobulin $\mathrm{AB}$ at neutral $\mathrm{pH}$. Int. Dairy J. 9:791-800.

Thomas, K., M. Aalbers, G. A. Bannon, M. Bartels, R. J. Dearman, D. J. Esdaile, T. J. Fu, C. M. Glatt, N. Hadfield, C. Hatzos, S. L. Hefle, J. R. Heylings, R. E. Goodman, B. Henry, C. Herouet, M. Holsapple, G. S. Ladics, T. D. Landry, S. C. MacIntosh, E. A. Rice, L. S. Privalle, H. Y. Steiner, R. Teshima, R. van Ree, M. Woolhiser, and J. Zawodny. 2004. A multi-laboratory evaluation of a common in vitro pepsin digestion assay protocol used in assessing the safety of novel proteins. Regul. Toxicol. Pharmacol. 39:87-98.

Xiong, Y. L., K. A. Dawson, and L. Wan. 1993. Thermal aggregation of $\beta$-lactoglobulin: Effect of $\mathrm{pH}$, ionic environment and thiol reagent. J. Dairy Sci. 76:70-77.

Zeece, M., T. Huppertz, and A. Kelly. 2008. Effect of high-pressure treatment on in vitro digestibility of $\beta$-lactoglobulin. Innov. Food Sci. Emerg. Technol. 9:62-69. 